\title{
Clinical Pharmacist and Physician Team Collaboration to Improve Medication Safety and Cost Savings in an Inpatient Medicine Unit: A Prospective Cohort Study
}

\author{
Sumana Alex, Jennifer C. Kerns, Ayne B. Adenew, Cherinne Arundel \\ Internal Medicine VA Medical Center, Washington, DC 20422, USA
}

\begin{abstract}
Background: To prevent adverse drug events and promote patient safety, medication reconciliation is critical in all patient care settings. The purpose of this study was to identify medication discrepancies occurring in an inpatient medicine unit and to analyze the clinical and economic benefit of clinical pharmacist and physician team collaboration. Methods: A prospective cohort study in which pharmacist attended daily team rounds and assisted with medication management and medication reconciliation on admission and discharge in an academic hospital with internal medicine residents. All interventions related to medication management were categorized based on error type, severity of harm, preventable, non-preventable and potential adverse drug events. The economic outcome associated with these medication errors was analyzed. Results: There were 160 admissions and 179 pharmacist recommendations with a $91 \%$ acceptance rate from physicians. There were 145 discharges during the study period of which 104 medication discrepancies were identified. Eighty nine of the medication discrepancies were corrected by the pharmacist within 72 hours of discharge. Pharmacist identified 11 actual adverse drug events. Cost savings from pharmacist interventions during the study period was $\$ 11,652$ and cost avoidance from intercepting potential and actual adverse drug events was $\$ 256,806$. Conclusion: Collaboration of pharmacist with a physician team improved medication safety and led to significant cost savings and cost avoidance.
\end{abstract}

Key words: Medication reconciliation, pharmacist intervention, medication errors, economic benefit, collaboration

\section{Introduction}

In 2010, The National Priorities Partnership convened by the National Quality Forum reported that approximately 3.8 million inpatient admissions and 3.3 million outpatient visits were related to serious preventable medication errors, costing approximately $\$ 21$ billion [1]. Approximately $\$ 16.4$ billion annually is attributed to preventable inpatient medication errors and $\$ 4.2$ billion to outpatient errors [1]. Though hospitals have incorporated several strategies to minimize medication errors, including the use of electronic medical records, computerized order entry systems and bar coded medications with bedside scanning for administration, many medication errors

Corresponding author: Sumana Alex, Pharm. D., research field: clinical pharmacy, internal medicine. E-mail: Sumana.alex@va.gov. remain unidentified and unreported.

Medication reconciliation is critical for patient safety and prevention of ADEs (adverse drug events) and should be an integral part of care transitions in all patient care settings. Accurate and effective medication reconciliation, along with medication counseling, is vital for patient safety. The medication reconciliation process should incorporate communication among healthcare professionals during care transitions. Several studies involving clinical pharmacists in medication reconciliation and medication management have demonstrated that pharmacists provide both clinical and economic benefit to the institution and to patients [2-12]. While the significance of medication reconciliation by pharmacists is well-described, there are few published prospective studies on the impact of a clinical 
pharmacist collaborating with an internal medicine resident team throughout the hospitalization and discharge [9]. Furthermore, there are no prospective studies performed at a VA (veterans affairs) hospital using a team based approach with internal medicine residents and clinical pharmacists.

An institutional baseline review of the discharge medication instructions at the DC VAMC (District of Columbia VA Medical Center) revealed that close to $75 \%$ of discharge instructions had medication discrepancies at the time of discharge. The reasons underlying the occurrence of the medication discrepancies were not clearly understood.

The purpose of the prospective cohort study was to identify medication discrepancies from admission to discharge occurring in an internal medicine unit and analyze the clinical and economic impact of clinical pharmacist's collaboration with inpatient physicians in medication management.

\section{Methods}

\subsection{Study Setting}

The DC VAMC is a teaching facility with 74 medical beds and an average of 400 discharges per month. There are six medicine teams supervised by an attending physician employed by the DC VAMC. Each medical team is comprised of a senior resident, interns, and medical students who rotate from various academic institutions for 4 weeks. Our patient population primarily consists of elderly patients, many of whom have limited education and knowledge about their diseases and/or medications [13]. Therefore, medication understanding and compliance, monitoring of therapy, and follow-up is a challenge.

The CPRS (Computerized Patient Record System) is a national electronic health record that has been in use at the DC VAMC for many years; it affords care providers access to patients' outpatient medication regimens from our own hospital, other VA hospitals, and the Department of Defense Medical System. All medications ordered through CPRS are verified through the Veterans Health Information Systems and Technology Architecture (VistA) by pharmacists and are visible to providers on CPRS. It is therefore important for care providers to collaborate with pharmacists before orders are verified to prevent medication errors and improve patient care.

\subsection{Data Collection}

This study was approved by the DC VAMC Institutional Review Board and conducted for 3 months from August 1st 2012 to October 31st 2012 in one of the six teams on the internal medicine wards. Baseline data collection consisted of printed computerized outpatient medication lists on admission for all patients on the study team. The list helped identify medication discrepancies by capturing all medication information including inpatient, outpatient, and non-VA obtained medications. After this data was collected, the clinical pharmacist on the study team interviewed patients to obtain a complete medication history and used this in addition to the computerized record to reconcile medications at the time of admission. The pharmacist also monitored inpatient drug therapy, attended team rounds and assisted with discharge medication reconciliation and discharge orders. The pharmacist reviewed all discharges on the intervention team and resolved discrepancies either prior to or within 72 hours of discharge. The pharmacist counseled all patients about their discharge medications prior to discharge except those patients discharged outside of the pharmacist's normal work hours. The pharmacist also contacted high-risk patients after discharge, reminded them to keep their clinic appointments, and reiterated the importance of medication compliance. All interventions related to medication management during the study period were documented in the computerized patient profile.

\subsection{Data Analysis}

Using a consensus approach, all recommendations related to medication management were categorized 
by two physician hospitalists and a second clinical pharmacist not involved with patient care on the study team. Each intervention related to a medication error was classified based on error type and severity of harm using the National Coordinating Council for Medication Error Reporting (NCC MERP) Index for categorizing medication errors algorithm [14]. This categorization involves nine categories of medication errors based on severity and patient outcomes; NCC-MERP category A to C do not cause harm, category $\mathrm{D}$ errors require monitoring to preclude harm and category E-I are potential harm categories.

Adverse drug events (ADEs) identified and intervened upon by the clinical pharmacist were classified into preventable versus non-preventable using criteria from Shumock and Thornton [15]. Preventable ADEs are drug events that produce harm and are related to medication errors, lack of monitoring and drug interactions. Non-preventable ADEs are idiosyncratic reactions to a drug that could not be avoided [15-17]. Potential ADEs are medication errors that have the potential to cause harm, but were intercepted by pharmacist's intervention or before reaching the patient $[16,17]$. Our events were assigned probability of harm scores which were adapted from other studies [3, 7, 18-20] with few modifications and ranged from 0.1 to 1 . A probability of harm score of 1 was given to an actual ADE identified and intercepted by the clinical pharmacist [3, 7]. For potential ADEs, the probability of harm score was set at 0.1 (for low probability), 0.5 (intermediate) and 0.9 (high) (Appendix A).

The economic impact of the pharmacist interventions was evaluated by using direct cost savings and an estimate of indirect cost avoidance. To calculate cost avoidance, the probability of harm scores for actual ADEs were multiplied by the number of interventions and the estimated cost of preventable and non-preventable ADEs as reported by Bates et al. [16]. The cost of a preventable ADE was estimated as $\$ 6,701$ and a non-preventable ADE \$3,712 after adjusting for inflation using the 2012 consumer price index. The cost avoidance from interventions related to potential ADEs was calculated by multiplying the probability of harm score by the number of interventions and the cost of a preventable ADE.

Cost savings was calculated by multiplying the differences in medication acquisition costs related to the interventions by the duration of therapy as described by Lee et al. [7]. Labor cost of $\$ 3.73$ for filling and processing each prescription was added to this value. The labor cost estimate was based on data collected by Lee et al. [7] and adjusted for inflation using the 2012 consumer price index. Because our costs may be lower at the VA health system, we calculated cost savings if the same interventions had occurred in a neighboring hospital.

The direct medical costs incurred to the hospital for the treatment of ADEs were calculated from the actual cost of the individual patients' hospitalization obtained from the business office at our institution.

\section{Results}

The study team had 160 admissions during the three-month period and 179 pharmacist recommendations with a $91 \%$ acceptance rate from physicians. The majority of discrepancies noted during the inpatient stay were related to incorrect medication dosing, untreated diagnosis, drug omissions, and ADE's (Fig. 1). There were 145 patients discharged and 104 discharge related medication discrepancies identified. The most common discharge related medication discrepancies were lack of notification to the patient about medication changes, inaccurate discharge medication lists, and extraneous medication (Fig. 2). Eighty nine of these errors were corrected by the pharmacist within 72 hours of discharge. Of the 145 discharges, 97 patients had no medication discrepancies at the time of discharge and an additional 39 patients had no discrepancies after correction by the pharmacists prior to the patient's discharge or within 72 hours of discharge. 


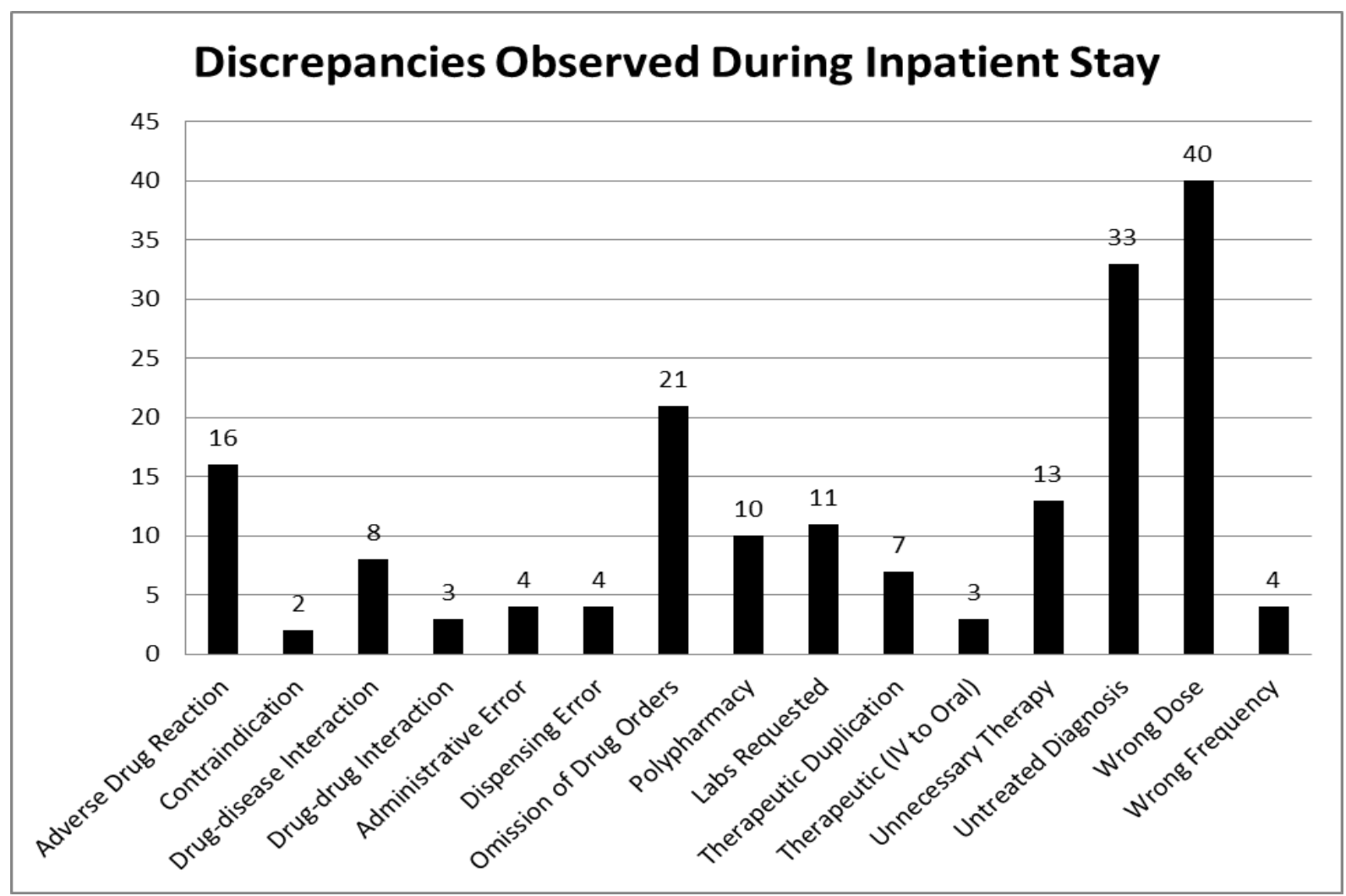

Fig. 1 Discrepancies observed during inpatient stay.

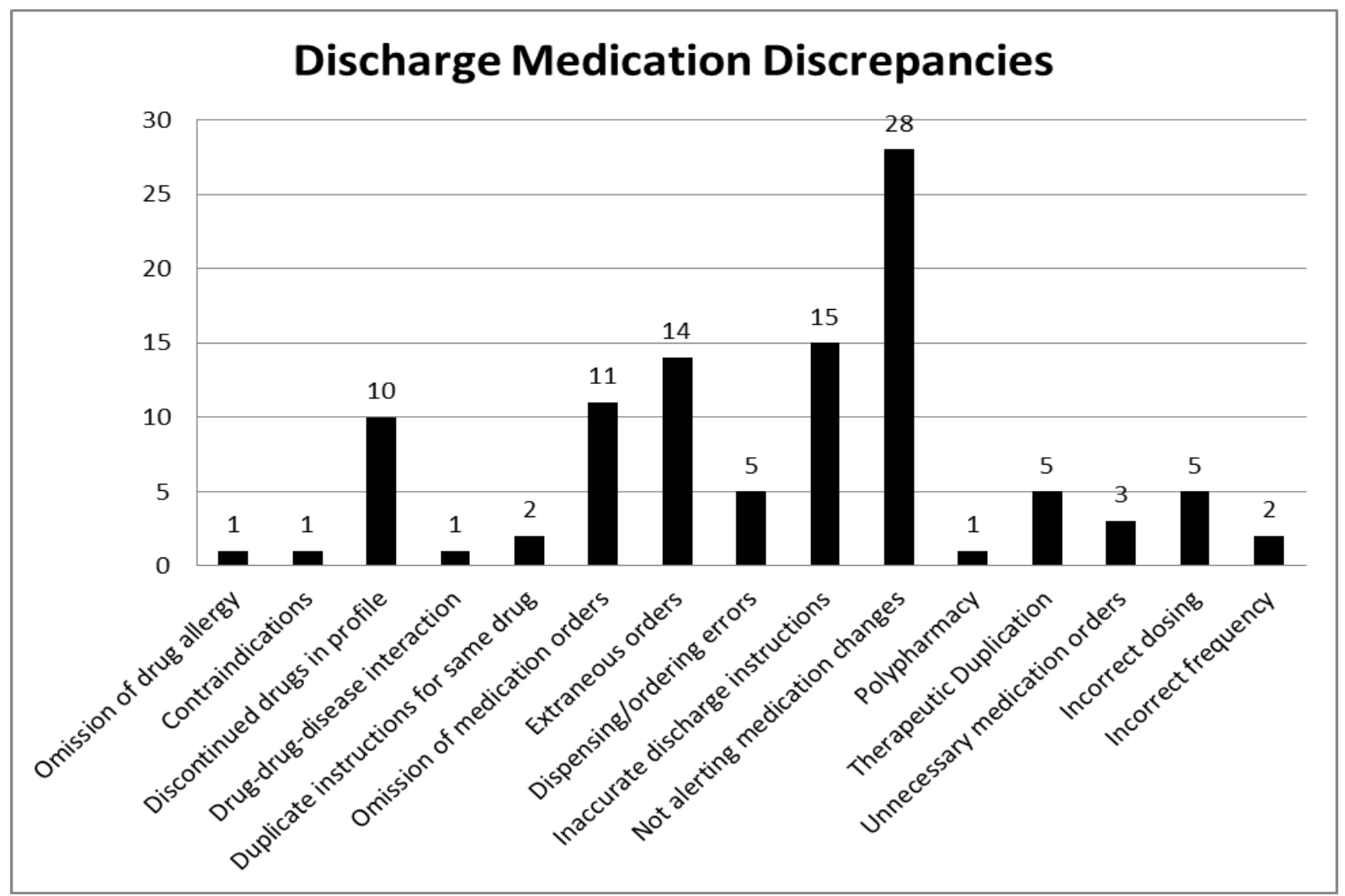

Fig. 2 Discharge medication discrepancies. 
Overall, 93.8\% (136/145) of discharged patients did not have discharge related medication discrepancies within 72 hours of discharge. Attempts were made to address discrepancies in the remaining nine discharges; however, the patients could not be reached.

We categorized a total of 156 inpatient recommendations and 20 discharge-related recommendations according to the NCC-MERP [14] index as follows: $\mathrm{A}=4, \mathrm{C}=76, \mathrm{D}=44, \mathrm{E}=22, \mathrm{~F}=$ 29 and $\mathrm{I}=1$. Since interventions in the A-C category do not cause harm, they were not included in cost avoidance calculations. Eighty-seven interventions from

Table 1 Examples of pharmacist interventions.

\begin{tabular}{|c|c|c|c|c|}
\hline Intervention category & Drug/reaction & Intervention & $\begin{array}{l}\text { Probability of } \\
\text { harm score }\end{array}$ & Severity \\
\hline Preventable ADE & $\begin{array}{l}\text { Pregabalin overdose: } \\
\text { Fall leading to eye rupture and surgery } \\
\text { after increase in pregabalin dose. Patient } \\
\text { was also on gabapentin renal dosing. }\end{array}$ & $\begin{array}{l}\text { Patient with end stage renal disease: } \\
\text { Pregabalin dose was higher than the } \\
\text { recommended dose for dialysis patient. } \\
\text { Pregabalin dose adjusted prior to } \\
\text { discharge. }\end{array}$ & 1 & $S$ \\
\hline Non-preventable ADE & $\begin{array}{l}\text { Acetazolamide: } \\
3 \text { days prior to admission, patient was } \\
\text { started on acetazolamide. Patient } \\
\text { developed nausea, vomiting, acidic taste } \\
\text { and increase in creatinine to } 5.7 \mathrm{mg} / \mathrm{dL} \\
\text { from } 0.9 \mathrm{mg} / \mathrm{dL}\end{array}$ & $\begin{array}{l}\text { Identified acetazolamide as the } \\
\text { offending agent and recommended to } \\
\text { discontinue. }\end{array}$ & 1 & $S$ \\
\hline Untreated diagnosis & $\begin{array}{l}\text { Primary aldosteronism: } \\
\text { Patient was admitted for chest pain and } \\
\text { uncontrolled blood pressure on five } \\
\text { medications for hypertension. Upon } \\
\text { admission, patient with untreated } \\
\text { aldosteronism was hypokalemic with a } \\
\text { level of } 2.7 \mathrm{mmol} / \mathrm{L} \text { despite being on } \\
\text { potassium supplement. }\end{array}$ & $\begin{array}{l}\text { Recommended to discontinue } \\
\text { hydralazine, clonidine. Start } \\
\text { spironolactone for aldosteronism. }\end{array}$ & 0.9 & $S$ \\
\hline $\begin{array}{l}\text { Drug-disease } \\
\text { interaction }\end{array}$ & $\begin{array}{l}\text { Patient with cirrhosis, portal } \\
\text { hypertension, esophageal varices and } \\
\text { gastroduodenitis was admitted with } \\
\text { hemoglobin of } 6.5 \mathrm{gm} / \mathrm{dL} \text { and was on } \\
\text { naproxen } 375 \mathrm{mg} \text { twice daily before } \\
\text { admission. }\end{array}$ & $\begin{array}{l}\text { Naproxen was not discontinued from } \\
\text { the outpatient profile on discharge. } \\
\text { Recommended to discontinue naproxen. }\end{array}$ & 0.9 & $S$ \\
\hline $\begin{array}{l}\text { Wrong drug use } \\
\text { instructions/duplicate } \\
\text { treatment }\end{array}$ & $\begin{array}{l}\text { COPD exacerbation: } \\
\text { Patient was admitted for exacerbation of } \\
\text { chronic obstructive lung disease (COPD). }\end{array}$ & $\begin{array}{l}\text { 1. Reviewing the chart, it was identified } \\
\text { that patient was using aero chamber } \\
\text { with budesonide/salmeterol inhaler as } \\
\text { instructed by the clinic. Since this } \\
\text { inhaler comes in dry powder, aero } \\
\text { chamber would be a wrong drug } \\
\text { delivery system. } \\
2 \text {. Two inhaled steroids were ordered. } \\
\text { Recommended to discontinue the } \\
\text { aerochamber and mometasone and } \\
\text { increase budesonide/salmeterol to the } \\
\text { recommended dose for COPD. }\end{array}$ & 0.5 & IS \\
\hline Drug omission & $\begin{array}{l}\text { Patient with atrial fibrillation controlled } \\
\text { on diltiazem } 360 \text { mg daily at home and } \\
\text { diltiazem was not started on admission. }\end{array}$ & Recommended to restart diltiazem. & 0.5 & IS \\
\hline Duplicate treatment & $\begin{array}{l}\text { Patient was discharged on mometasone } \\
\text { and budesonide/salmeterol inhaler. }\end{array}$ & $\begin{array}{l}\text { Contacted the patient and advised to } \\
\text { discontinue mometasone. }\end{array}$ & 0.1 & LR \\
\hline Wrong dose/frequency & $\begin{array}{l}\text { Piperacillin/ } \\
\text { tazobactam: } \\
\text { Renal dosing on admission due to } \\
\text { creatinine of } 2.4 \mathrm{mg} / \mathrm{dL} \text {. Renal dosing } \\
\text { was continued after creatinine decreased } \\
\text { to baseline } 1.3 \mathrm{mg} / \mathrm{dL} \text {. }\end{array}$ & $\begin{array}{l}\text { Recommended to change dosing for } \\
\text { normal renal function. }\end{array}$ & 0.1 & LR \\
\hline
\end{tabular}


Table 2 Overall cost avoidance from pharmacy interventions.

\begin{tabular}{|c|c|c|c|c|c|}
\hline & $\begin{array}{l}\text { Number of } \\
\text { interventions }\end{array}$ & $\begin{array}{l}\text { Cost of one } \\
\operatorname{ADE}(\$)\end{array}$ & $\begin{array}{l}\text { Actual Cost } / 3 \\
\text { months }(\$) \text { for } 1 \\
\text { team }\end{array}$ & $\begin{array}{l}\text { Annualized cost } \\
\text { avoidance }(\$) \text { for } 1 \\
\text { medicine team }\end{array}$ & $\begin{array}{l}\text { Extrapolated cost } \\
\text { for } 6 \text { teams }\end{array}$ \\
\hline Cost savings from interventions & 83 & N/A & 9,714 & 38,856 & 233,136 \\
\hline $\begin{array}{l}\text { Cost savings from preventing medication } \\
\text { processing for nursing home discharges }\end{array}$ & 2 & N/A & 1,938 & 7,752 & 46,512 \\
\hline $\begin{array}{l}\text { Cost avoidance from identifying and } \\
\text { ameliorating preventable ADEs } \\
\text { (probability score } 1 \text { ) }\end{array}$ & 5 & 6,701 & 33,505 & 134,020 & 804,120 \\
\hline $\begin{array}{l}\text { Cost avoidance from identifying and } \\
\text { ameliorating non-preventable ADEs } \\
\text { (probability score } 1 \text { ) }\end{array}$ & 6 & 3,712 & 22,272 & 89,088 & 534,528 \\
\hline $\begin{array}{l}\text { Cost avoidance from identifying potential } \\
\text { severe ADEs (probability score } 0.9 \text { ) }\end{array}$ & 23 & 6,701 & 138,710 & 554,840 & $3,329,040$ \\
\hline $\begin{array}{l}\text { Cost avoidance from identifying potential } \\
\text { intermediate severe ADEs (probability } \\
\text { score } 0.5 \text { ) }\end{array}$ & 10 & 6,701 & 33,505 & 134,020 & 804,120 \\
\hline $\begin{array}{l}\text { Cost avoidance from identifying potential } \\
\text { low risk ADEs (probability score } 0.1 \text { ) }\end{array}$ & 43 & 6,701 & 288,14 & 115,256 & 691,536 \\
\hline Total & & & 268,458 & $1,073,832$ & $6,442,992$ \\
\hline
\end{tabular}

NCC-MERP categorization D, E and F were selected for assigning probability of harm scores and cost avoidance calculation. The medication error in the I category was excluded since the error occurred during off duty time of the clinical pharmacist and there was no intervention. Assigning a probability of harm score for eight recommendations in category D was deemed too difficult by the primary investigator and excluded from analysis. There were 11 actual ADEs identified and intervened by the clinical pharmacist. Five ADEs were preventable and six non-preventable. Table 1 lists a few examples of selected interventions by the clinical pharmacist.

There were 15 interventions related to anticoagulants. They involved duplicate treatment with warfarin and LMWH (low molecular weight heparins) despite therapeutic and supra-therapeutic INRs, drug interactions necessitating dose adjustments, continuation of warfarin beyond the necessary treatment duration, discharge of patients without instructions on restarting warfarin, and dose/frequency errors with injectable anticoagulants.

Cost savings from pharmacist interventions during the 3 months study period in the team were $\$ 11,652$ (Table 2), which would have been approximately $\$ 27,610$ if the same study and interventions were conducted in a nearby private hospital. This difference was due to the lower acquisition cost of the medications available to us as a government hospital. The cost avoidance from intercepting actual and potential ADEs was $\$ 256,806$.

The direct cost incurred to our hospital for the treatment of the 11 actual ADEs during the study period was $\$ 186,121$. The extrapolated cost over a year on all six inpatient teams would have been approximately $\$ 4.5$ million.

\section{Discussion}

Medication errors are common and our study highlights collaboration between pharmacists and physicians can have a significant impact on clinical and economic outcomes. The pharmacist identified 11 actual adverse events and 76 potential ADEs which would have remained unrecognized by the care providers, likely resulting in recurrent ADEs and possibey readmissions. These were associated with significant cost avoidance due to early identification of the adverse events. There were 104 discharge-related interventions which included correction of incomplete/inaccurate discharge instructions, alerting patients of medication changes and updating outpatient medication lists. These 
discharge related interventions were not included in our cost avoidance calculation due to difficulty in assessing prospective harm that might occur in the absence of pharmacist interventions. Therefore, it is likely that these interventions would have had even greater economic impact than our calculations suggest, by preventing $\mathrm{ADEs}$ and potential readmissions.

Of note, the probability of harm scores in the study did not necessarily correlate with the severity of the medication errors based on NCC-MERP categorization. For example, the intervention in which a patient continued to receive warfarin for 7 months beyond the required treatment duration was MERP category E, but was given a probability of harm score of 0.9. Another patient who had an INR of 4.0 on admission and continued to receive enoxaparin while warfarin was on hold received a probability of harm score of 0.9, but was in the MERP category D.

Prospective data collection, the availability of an electronic health record, access to medication information from various sources such as primary care, other VA's, Department of Defense are all advantages of our study. Furthermore, the investigators were able to identify the actual cost of an adverse drug event. Cost savings and cost avoidance related to medication errors may also be generalizable to other practice areas within the Veteran's Administration and similar academic settings.

Our study has various limitations. The probability of harm score was based on a scale used in other studies with minor modifications. A degree of subjectivity was involved in determining the probability of harm scores since they depend on patient risk, comorbidities, medication dose, medication side effects, indication for treatment and speculation of potential harm.

Methods used for cost avoidance and cost savings calculations were another limitation of our study. Cost savings were calculated based on the cost of the medications and did not include additional equipment such as intravenous fluids needed for medication delivery. The additional cost incurred related to pharmacist interventions was not deducted from the cost savings calculation since this cost was negligible. The pharmacist salary was not subtracted from the cost savings since the pharmacist was assigned to work in the inpatient medicine unit. The extra hours the pharmacist used for patient care during the study period beyond the regular work schedule were also not considered in cost savings calculations. For cost avoidance calculations, we used the cost of an ADE provided in the study by Bates et al. [16], which was based on a private setting. This may have over-estimated our cost avoidance values since we are a government facility. Since it was difficult to determine how many discharge related discrepancies would have actually resulted in clinically significant ADEs in the absence of the clinical pharmacist intervention, only 11 out of the 89 discrepancies corrected by the pharmacist were selected for cost avoidance calculations.

Our study period was short and the sample size was relatively small. The study involved a single pharmacist and one medical team which may not reflect variability in individual skills and experience. The intervention team was blinded to the study, yet the presence of a clinical pharmacist rounding with the team may have introduced bias. Future research could involve multiple veteran sites, a larger sample size, and evaluation of patient specific interventions.

\section{Conclusion}

Collaboration of a pharmacist with a physician team showed a reduction in medication errors and had a significant impact on cost savings. The cost savings and cost avoidance generated by the pharmacist justified the expense of additional clinical pharmacist coverage of the medicine units and demonstrate the need for stronger collaboration between the care providers and the clinical pharmacists.

\section{References}

[1] National Priorities Partnership and National Quality 


\section{Clinical Pharmacist and Physician Team Collaboration to Improve Medication Safety and Cost Savings in an Inpatient Medicine Unit: A Prospective Cohort Study}

Forum. 2010. "Preventing Medication Errors: A \$21 Billion Opportunity." National Quality Forum. Accessed July, 2012. http://psnet.ahrq.gov/resource.aspx?resourceID=20529

[2] Kaboli, P. J., Hoth, A. B., McClimon, B. J., Schnipper, J. L. 2006. "Clinical Pharmacists and Inpatient Medical Care. A Systematic Review." Arch. Intern. Med. 166 (9): 955-64.

[3] Kopp, B. J., Mrsan, M., and Erstad, B. I. 2007. "Cost Implications of and Potential Adverse Events Prevented by Interventions of a Critical Care Pharmacist." Am. J. Health-Sys Pharmacy 64 (23): 2483-7.

[4] Dooley, M. J., Allen, K. M., Doecke, C. J., Galbraith, K. J., Taylor, G. R., Bright, J., and Carey, D. L. 2003. “A Prospective Multicenter Study of Pharmacist Initiated Changes to Drug Therapy and Patient Management in Acute Care Government Funded Hospitals." Br. J. Clin. Pharmacol. 57 (4): 513-21.

[5] Cornu, P. S., Steurbauf, S., Leysen, T., De Baere, E., Ligneel, C., Mets, T., and Dupont, A. G. 2012. "Effect of Medication Reconciliation at Hospital Admission on Medication Discrepancies during Hospitalization and at Discharge for Geriatric Patients." Ann. Pharmacother. 46 (4): 484-94.

[6] Kukukarslan, S. N., Peters, M., Mlynarek, M., and Nafziger D. A. 2003. "Pharmacists on Rounding Teams Reduce Preventable Adverse Drug Events in Hospital General Medicine Units." Arch. Intern. Med. 163 (17): 2014-8.

[7] Lee, A. J., Boro, M. S., Knapp, K. K., Meier, J. L., and Korman, N. E. 2002. "Clinical and Economic Outcomes of Pharmacist Recommendations in a Veterans Affairs Medical center." Am. J. Health-Syst. Pharm. 59 (21): 2070-7.

[8] Nesbit, T. W., Shermock, K. M., Bobek, M. B., Capozzi, D. L., Flores, P. A., Leonard, M. C., Long, J. K., Militello, M. A., White, D. A., Barone, L. D., Goldman, M. P., and Kvancz, D. A. 2001. "Implementation and Pharmacoeconomic Analysis of a Clinical Staff Pharmacist Practice Model." Am. J. of Health-Syst. Pharm. 58 (9): 784-90.

[9] Schnipper, J. L., Hamann, C., Ndumele, C. D., Liang, C. L., Carty, M. G., Karson, A. S., Bhan, I., Coley, C. M., Poon, E., Turchin, A., Labonville, S. A., Diedrichsen, E. K., Lipsitz, S., Broverman, C. A., McCarthy, P., and Gandhi, T. K. 2009. "Effect of an Electronic Medication Reconciliation Application and Process Redesign on Potential Adverse Drug Events: a Cluster-Randomized Trial.” Arch. Intern. Med. 169 (8): 771-780.

[10] Mergenhagen, K. A., Blum, S. S., Kugler, A., Livote, E. L., Nebeker, J. R., Ott, M. C., Signor, D., Sung, S., Yeh, J., and Boockvar, K. S. 2012. "Pharmacist-Versus
Physician-Initiated Admission Medication Reconciliation: Impact on Adverse Drug Events." Am. J. Geriatr. Pharmacother. 10 (4): 242-50.

[11] Heyworth, L., Paquin, A. M., Clark, J., Kamenker, V., Stewart, M., Martin, T., and Simon, S. R. 2014. "Engaging Patients in Medication Reconciliation via a Patient Portal Following Hospital Discharge." J. Am. Medical Inform. Assoc. 21 (el): e157-62.

[12] Hamblin, S., Rumbaugh, K.., and Miller, R. 2012. "Prevention of Adverse Drug Events and Cost Savings Associated with PharmD Interventions in an Academic Level 1 Trauma Center: An Evidence based Approach." J. Trauma. Acute Care Surg. 73 (6): 1484-90.

[13] "FAQ about Homeless Veterans." National Coalition for Homeless Veterans. Accessed July 3, 2012.

http://www.nchv.org/index.php/news/media/background_ and_statistics/.

[14] National Coordinating Council for Medication Error Reporting and Prevention. 2012. "NCC MERP Index for Categorizing Medication Errors Algorithm." Accessed April, 2012.

http://www.nccmerp.org/sites/default/files/algorBW200106-12.pdf

[15] Schumock, G. T., Thornton, J. P. 1992. "Focusing on the Preventability of Adverse Drug Reactions." Hosp. Pharm. 27(6): 538.

[16] Bates, D. W., Spell, N., Cullen, D. J., Burdick, E., Laird, N., Paterson, L. A., Small, S. D., Sweitzer, B. J., and Leape, L. L. 1997. "The Costs of Adverse Drug Events in Hospitalized Patients." JAMA 274 (4):307-11.

[17] Sensi, B. L., Achusim, L. E., Genest, R. P., Cosentino, L. A., Ford, C. C., Little, J. A., Raybon, S. J., and Bates, D. W. 2001. "Practical Approach to Determining Costs and Frequency of Adverse Drug Events in a Healthcare Network." Am. J. Health-Syst. Pharm. 58 (12): 1126-32.

[18] Lesselroth, B. J., Dorr, D. A., Adams, K., Church, V., Adams, S., Mazur, D., Russ, Y., Felder, R., Douglas, D. M. 2012. "Medication review Software to Improve the Accuracy of Outpatient Medication Histories: Protocol for a Randomized Controlled Trial." Human Factors and Ergonomics in Manufacturing and Service Industries. 22 (1): 72-86.

[19] Overhage, J. M., and Lukes, A. 1999. "Practical, Reliable, Comprehensive Method for Characterizing Pharmacists' Clinical Activities." Am. J. Health-Syst Pharm. 56 (23): 2444-9.

[20] Pippins, J. R., Gandhi, T. K., Hamann, C., Ndumele, C. D., Labonville, S. A., Diedrichsen, E. K., Carty, M. G., Karson, A. S., Bhan, I., Coley, C. M., Liang, C. L., Turchin, A., McCarthy, P. C., and Schnipper, J. L. 2008. "Classifying and Predicting Errors of Inpatient Medication Reconciliation.” J. Gen Intern. Med. 23 (9): 1414-22. 


\section{Appendix A}

Probability of Harm Score (P) Based on Severity for Actual and Potential ADEs

Actual ADEs ( $\mathbf{P}$ of harm score = 1): The adverse drug events (ADEs) identified and ameliorated by the intervention pharmacist categorized as either preventable or non-preventable.

Potential ADEs:

Severe (S: P of harm score = 0.9): An error that involved high-risk medications (narcotics, insulin, anticoagulants, anticonvulsants, electrolytes, cardiovascular drugs) that could result in risk of death or adverse events if not treated

- High dosage (>=10 times the normal dose range)

- Drug-drug or drug-disease interaction which are absolute contraindications

- Agents/doses with a high potential to cause cardiopulmonary arrest in the dose ordered

Intermediate Severity (IS: P of harm score = 0.5): An error that is not life threatening but the potential ADE is serious enough to cause alteration of daily function

- Route of administration could lead to severe toxicity or lack of response

- Discrepancies involving high risk medications

- Discrepancies involving doses $1 / 2$ times to 10 times the normal dosage

- Drug-drug or drug-disease interaction which are relative contraindications

- Unintentional duplication

Low Risk (LR: P of harm score $=\mathbf{0 . 1}$ ): An error that is potentially harmful to the patient, but of little threat

- Inappropriate dose and dosage interval

- Unclear discharge instructions

- Duplicate medication(s)

- Omission of medication(s)

- Polypharmacy 